\title{
Prevalence and factors associated with trachoma among children aged I-9 years in Zala district, Gamo Gofa Zone, Southern Ethiopia
}

This article was published in the following Dove Press journal:

Clinical Ophthalmology

29 August 2016

Number of times this article has been viewed

Kassahun Mengistu'

Mulugeta Shegaze ${ }^{2}$

Kifle Woldemichael ${ }^{3}$

Hailay Gesesew ${ }^{3,4}$

Yohannes Markos ${ }^{5}$

'Department of Zonal Health

Office, Gamo Goffa Zone, Arba

Minch, Ethiopia; ${ }^{2}$ Department of

Nursing, Arba Minch University, Arba

Minch, Ethiopia; ${ }^{3}$ Department of

Epidemiology, Jimma University, Jimma,

Ethiopia; ${ }^{4}$ Discipline of Public Health,

Flinders University, Adelaide, Australia;

${ }^{5}$ Department of Medical Physiology,

Jimma University, Jimma, Ethiopia
Correspondence: Yohannes Markos Department of Medical Physiology, Jimma University, PO Box 378, Jimma, Ethiopia Tel +25I 94I I89744 Email yohannestryI@gmail.com
Background: Trachoma is the leading cause of preventable blindness worldwide. It is common in areas where people are socioeconomically deprived. Globally, approximately 1.2 billion people live in trachoma-endemic areas, in which, 40.6 million individuals have active trachoma and 8.2 million have trichiasis. According to the World Health Organization's 2007 report, globally close to 1.3 million people are blind due to trachoma, while approximately 84 million suffer from active trachoma. The National Survey (2007) of Ethiopia showed a prevalence of $40.1 \%$ active trachoma among children aged 1-9 years. Trachoma is still endemic in most parts of Ethiopia. Objective: To assess prevalence of trachoma and factors associated with it among children aged 1-9 years in Zala district, Gamo Gofa Zone, Southern Nations, Nationalities, and Peoples' Region.

Methods: A community-based cross-sectional study was conducted in Zala district from February 28 to March 26, 2014. A total of 611 children were examined for trachoma based on the simplified World Health Organization 1983 classification. A multistage stratified sampling technique with a systematic random sampling technique was used to select study participants. Data were collected by using a semistructured pretested questionnaire and clinical eye examination. The data were entered using EpiData version 3.1 and analyzed using SPSS version 16. Multivariable logistic regression analysis was used to identify independently associated factors.

Results: The overall prevalence of active trachoma cases was 224 (36.7\%) consisting of 207 (92.4\%) trachomatous follicles, eight (3.6\%) trachomatous intense, and nine (4.0\%) combination of trachomatous follicle and trachomatous intense. Inadequate knowledge of family head about trachoma (adjusted odds ratio $[\mathrm{AOR}]=2.8[95 \% \mathrm{CI}: 1.9,4.2]) ; \leq 10 \mathrm{~m}$ latrine distance (AOR $=1.6$ [95\% confidence interval $\{\mathrm{CI}\}: 1.09,2.4])$; presence of above two preschool children (AOR $=2.2$ [95\% CI: 1.3, 3.7]), flies on the face (AOR $=6.3$ [95\% CI: 2.7, 14.7]), and unclean face (AOR $=2.4[95 \% \mathrm{CI}: 1.5,3.9])$ were found to be independently associated with trachoma.

Conclusion: Trachoma among children in Zala district is a disease of public health importance. Factors like inadequate knowledge about trachoma by the head of the family, $\leq 10 \mathrm{~m}$ latrine distance, presence of above two preschool children, flies on the face, and an unclean face were independently associated with trachoma among children. So strengthening of antibiotic use, face washing, and environmental improvement strategy implementation is mandatory.

Keywords: trachoma, children, prevalence, associated factors, Ethiopia

\section{Introduction}

Infectious diseases have been the most important contributor to human morbidity and mortality until relatively recent times, and still accounts for a large proportion of death and disability worldwide. In certain regions infectious diseases remains the most important cause of ill health and have been responsible for $22 \%$ of all deaths and $27 \%$ of 
disability-adjusted life years worldwide. ${ }^{1}$ They have imposed a burden on the young, notably on children under 5 years.

Eye problems are recognized as among one of the major public health challenges in many developing countries. An international initiative called VISION 2020: The Right to Sight was launched by the World Health Organization (WHO) and collaborating institutions in 1999 to eliminate the major causes of avoidable blindness by the year 2020 . $^{2,3}$ Ethiopia launched the initiative in September 2002.,5

Blindness is one of the major health problems of the world. In 2002, WHO estimated that there were 37 million blind people and an additional 124 million people with low vision globally. The burden of blindness in the sub-Saharan Africa region is some of the worst in the world. Seventy-five percent of all blindness in developing countries can be prevented or cured. The current (2012) National Survey Results have shown that the prevalence of blindness and low vision in Ethiopia is among the highest in the sub-Saharan Africa (1.6\% and $3.7 \%$, respectively). ${ }^{6}$ In Ethiopia, the prevalence of blindness is $1.6 \%$ and corneal blindness accounts for over $19 \%$ of the total blindness. ${ }^{6}$

Trachoma is the leading cause of blindness worldwide, especially in many developing countries. ${ }^{7}$ Trachoma is a chronic conjunctivitis caused by Chlamydia trachomatis. ${ }^{8}$ WHO has endorsed the Surgery, Antibiotic, Face Washing and Environmental Sanitation strategy to combat trachoma, which consists of surgery to correct trichiasis, antibiotics to reduce the pool of active disease, and methods to improve face washing and environmental hygiene practices in trachomaendemic communities. ${ }^{9}$ This study aimed to assess prevalence of trachoma and factors associated with it among children aged 1-9 years in Zala district, Gamo Gofa Zone, Southern Nations, Nationalities, and Peoples' Region, Ethiopia.

\section{Methods}

\section{Study setting, design, and sampling}

Community-based cross-sectional study was conducted among children aged 1-9 years in Gamo Gofa Zone of Southern Ethiopia from February 28 to March 26, 2014. Zala district is located $515 \mathrm{~km}$ south of Addis Ababa and $285 \mathrm{~km}$ south of regional city Hawassa. It is one of the 15 districts found in Gamo Gofa Zone. The district was administratively divided into 35 kebeles (lowest administrative units). There are 34 rural and one urban kebele. The district has 90,700 total population (51\% female and 49\% male).

Approximately $97 \%$ of the population lives in rural part of the district, where there is low infrastructure. The Gofa ethnic group is dominant in the area $(\sim 83 \%)$. As far as the climatic condition of the area is concerned, approximately
$91.5 \%$ is lowland and $8.5 \%$ is mid-highland. The district had five health centers (one urban and four rural) during the study time. There were 35 (34 rural and one urban) health posts, and four private clinics with potential health service coverage of $95 \%$. The district was provided with three round mass Zithromax distribution for trachoma elimination (Woreda, unpublished data, 2013).

The sample size was determined by using a single population proportion formula by considering $24.1 \%$ prevalence rate taken from a study done in Baso Liben district in East Gojjam Zone, in the northern part of Ethiopia. ${ }^{10}$ Ten percent nonresponse rates, 95\% confidence level with 5\% margin of error and design effect of two were considered. Based on this, a total of 618 children aged 1-9 years were selected for the study.

A multistage sampling technique was applied to select study subjects. After stratifying the district into urban and rural areas, one urban (only in the district) and nine rural kebeles were randomly selected using lottery method. The total sample was allocated proportionally to the selected ten kebeles according to their population size. A total of 6,337 households were present in the selected ten kebeles and 618 households were visited and one child per house was included in the study. Systematic random sampling method was used to select study units.

The following procedure was applied to get the households of the study subjects. First, a central point in each kebele; a place in the kebele where approximately an equal number of households were found in all of the four directions; was identified. Then, by spinning a pencil on a clipboard, a direction was identified and the first household out of the first ten households was selected as starting point. A direction was identified, and then the first household out of the first ten households was selected as starting point. Every tenth household was identified for inclusion into the study on an approximately straight line pattern in each kebele. Ten households on the selected direction were listed and a random start household number was identified by simple random sampling method. Then, every tenth household was selected and included into the study. This procedure was continued in all the selected kebeles until the required sample was gained for each of the kebeles. When there are no children aged 1-9 years in a sampled household, a substitute is taken from the nearest household. If there were two or more children in a household, one of them was selected by lottery method.

A total of 611 households were included and heads of households were interviewed for sociodemographic and economic information, housing and environmental condition, knowledge and practice about prevention of trachoma and 
child factors. A total of 611 children were examined for the trachoma status from the ten selected kebeles accordingly.

\section{Data collection and measurement}

Face-to-face interview, observation with checklist, and clinical eye examination method of data collection were used. Data were collected using a pretested interviewer-administered semistructured questionnaire by trained and integrated eye care workers (nurses) as recorders, and ophthalmic nurses who were licensed and who participated in global mapping trachoma grading for eye examination. The questionnaire was adapted into local settings by reviewing related literature.

The clinical eye examination of each study subject was done by ophthalmic nurse trachoma graders. Careful inspection of eyelashes, cornea, limbus, eversion of the upper lid, and inspection of the tarsal conjunctiva with the help of magnifying binocular lenses $(\times 2.5)$ and penlight torches were carried out. The guide used for diagnosis and reporting of eye examination results was the simplified trachoma grading scheme, which was developed by WHO for field work. ${ }^{11}$ The interrater variability of eye examination was solved by certified trachoma graders who participated in the national program.

The questionnaires were pretested before the actual data collection. Five integrated eye care workers were recruited and trained to interview head of the households and observe the children after getting written consents from the heads of households. Then, two ophthalmic nurses who are trachoma graders also took part in eye examination.

\section{Statistical analysis}

Data were entered using EpiData version 3.1 (The EpiData Association, Odense, Denmark). It was then edited and cleaned for inconsistencies, missing values, outliers and then exported for analysis to SPSS version 16 (SPSS Inc., Chicago, IL, USA). Bivariate logistic regression analysis was done to determine the presence of statistical association between independent variables and the outcome variable and its strength with direction. Variables with $P<0.25$ in bivariate analysis were considered as candidates to be entered into multivariable logistic regression model. The final model was fitted using stepwise selection methods (backward logistic regression). $P \leq 0.05$ in multivariable logistic regressions was considered as statistically significant. Goodness of fitness of the model was checked by Hosmer-Lemeshow test.

\section{Ethical consideration}

Ethical approval and clearance was obtained from Jimma University Ethical Review Board. Letter of cooperation was obtained from Zala district health office and Zala district administration office. Written informed consent was taken from the head of the household. Children with trachoma were provided with two tubes of $1 \%$ tetracycline eye ointments immediately after examination and referred to a linked to primary eye care unit.

\section{Results \\ Sociodemographic and economic characteristics}

A total of 611 children were seen for an eye examination and this made the response rate $98.87 \%$. The remaining households were not included due to refusal to participate in the study and incomplete data in the analysis.

The majority of household heads, 473 (77.4\%), were females with the mean age of $31 \pm 7$ years; approximately half of them, 326 (53.4\%), were illiterate; and 565 (92.5\%) were married. They were predominantly rural residents, 551 $(90.2 \%)$, with the average family size of six (Table 1$)$.

Table I Sociodemographic characteristics of the head of the household in Zala district from February 28 to March 26, 2014

\begin{tabular}{|c|c|c|}
\hline Variable & Frequency $(n=6 I I)$ & Percentage \\
\hline \multicolumn{3}{|l|}{ Sex } \\
\hline Male & 138 & 22.6 \\
\hline Female & 473 & 77.4 \\
\hline \multicolumn{3}{|l|}{ Educational status } \\
\hline Illiterate & 326 & 53.4 \\
\hline Read and write & 9 & 1.5 \\
\hline First cycle I-4 grades & 103 & 16.9 \\
\hline Second cycle 5-8 grades & 109 & 17.8 \\
\hline Grade 9 and above & 64 & 10.5 \\
\hline \multicolumn{3}{|l|}{ Marital status } \\
\hline Married & 565 & 92.5 \\
\hline Divorced & 19 & 3.1 \\
\hline Widowed & 27 & 4.4 \\
\hline \multicolumn{3}{|l|}{ Occupation } \\
\hline Governmental worker & 41 & 6.7 \\
\hline Farmer & 372 & 60.9 \\
\hline Merchant & 26 & 4.3 \\
\hline Housewife & 165 & 27.0 \\
\hline Others & 7 & I.I \\
\hline \multicolumn{3}{|l|}{ Place of residence } \\
\hline Urban & 60 & 9.8 \\
\hline Rural & 551 & 90.2 \\
\hline \multicolumn{3}{|l|}{ Family size } \\
\hline $2-5$ & 254 & 41.6 \\
\hline $6-10$ & 348 & 57.0 \\
\hline$>10$ & 9 & 1.5 \\
\hline \multicolumn{3}{|c|}{ Average monthly income } \\
\hline First quartile & 144 & 23.6 \\
\hline Second quartile & 155 & 25.4 \\
\hline Third quartile & 134 & 21.9 \\
\hline Fourth quartile & 178 & 29.1 \\
\hline \multicolumn{3}{|c|}{ Age of head of household (years) } \\
\hline $17-30$ & 54.0 & 54.0 \\
\hline $31-45$ & 43.0 & 43.0 \\
\hline $46-65$ & 2.9 & 2.9 \\
\hline
\end{tabular}




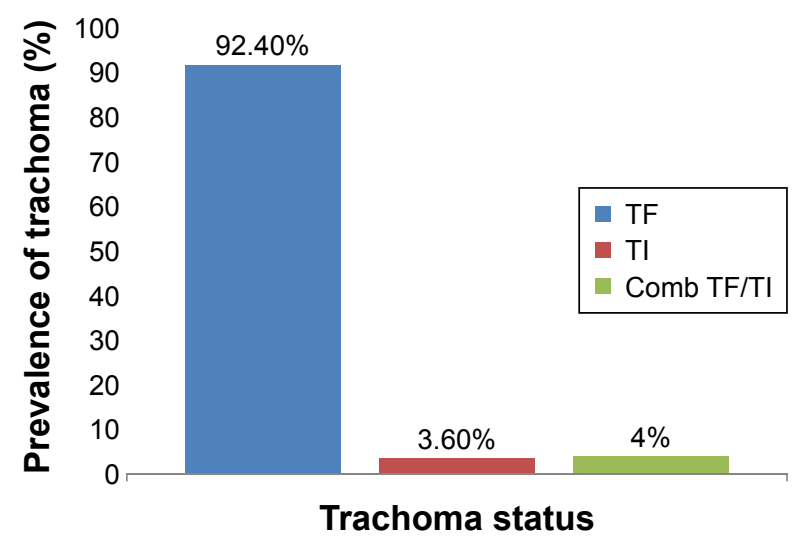

Figure I Prevalence of trachoma in children aged I-9 years in Zala district, Gamo Gofa Zone, Southern Ethiopia from February 28 to March 26, 2014.

Abbreviations: Comb, combination; TF, trachomatous follicle; TI, trachomatous intense.

\section{Prevalence of trachoma among children aged I-9 years}

Among all children examined for trachoma status, 224 (36.7\%) children had clinical trachoma. Among these, 207 (92.4\%), eight (3.57\%), and nine (4.0\%) were trachomatous follicle (TF), trachomatous intense (TI), and combination of TF/TI, respectively. Generally, overall prevalence of trachoma in the district was $36.7 \%$. There were no trachomatous scare (TS), trachomatous trichiasis (TT), and corneal opacity (CO) stages observed during the study (Figure 1).

\section{Knowledge of heads of households about trachoma}

The majority of the heads of the households, 592 (92.6\%), had heard about trachoma before the study time, but only $366(59.9 \%)$ of them had adequate knowledge about trachoma (Figure 2).

\section{Household environmental characteristics}

Most households used pipeline water, 388 (63.5\%), and more than half of them, 364 (59.6\%), traveled $<30$ minutes to fetch water. Approximately 239 (39.1\%) collected 20-40 L/day with the average consumption of $6 \mathrm{~L} /$ capita/day.
Majority of households, 585 (95.5\%), had latrine, of which 582 (99.5\%) were functional and 134 (33.2\%) were covered with traditional pit latrine. Five hundred ninety-one (96.7\%) households used latrine always and most of the latrines were located at the distance of $\leq 10 \mathrm{~m}$.

Majority of the households, $551(90.2 \%)$, had waste disposal system, among which 418 (76\%) used farmland disposal system. As far as the distance is concerned, 422 $(69.1 \%)$ of the households disposed the waste at a distance of $>10 \mathrm{~m}$ from their houses.

Flies were observed in half (50.2\%) of the households and the major $(60.7 \%)$ breeding site for the flies was animal dung. Even though three out of five households did use separate place for cooking, almost all of them, 592 (96.9\%), were without windows (Table 2).

\section{Child characteristics}

Child factor of trachoma among children in the study area is indicated in Table 3. Most of the children, 325 (53.2\%), were females with the mean age of $3 \pm 1$ years and there were an average of two preschool children per household. Preschool children were 517 (91.2\%), those who were attending school during the study time 27 (4.4\%), and those who were not attending even if eligible for primary education were also 27 (4.4\%).

Children who washed their face more than once a day were $523(85.6 \%)$. Five hundred nine $(83.3 \%)$ of the children had no ocular discharge, and 502 (82.2) had no nasal discharge (Table 3).

\section{Independent determinants of trachoma in children aged $\mathrm{I}-9$ years}

Knowledge about trachoma, latrine distance from household, number of preschool children, flies on the face of child, and facial cleanliness of the child were independently associated factors with trachoma among children.

Knowledge about trachoma was significantly associated with trachoma. Those children from household head having

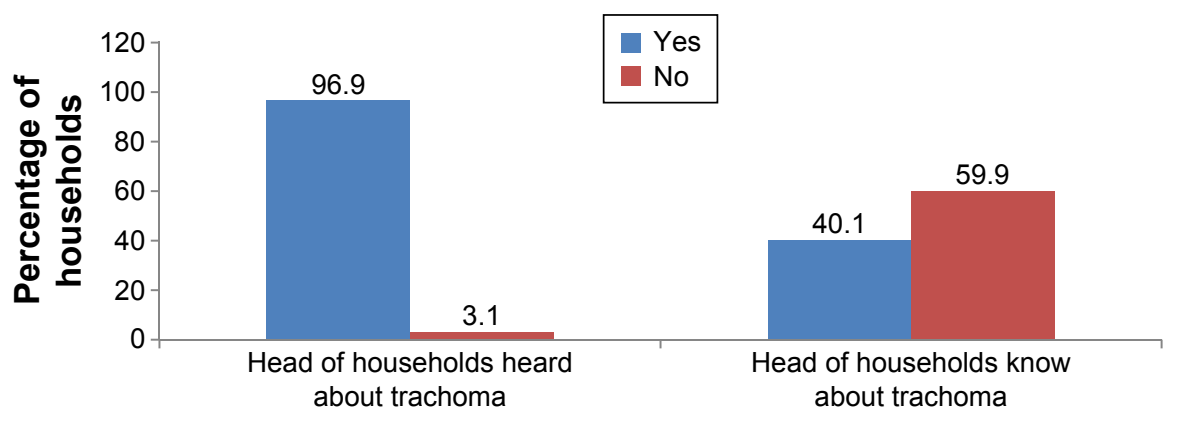

Figure 2 Knowledge of heads of households (HHs) about trachoma in Zala district from February 28 to March 26, 2014. 
Table 2 Household environmental factors of trachoma among children in Zala district from February 28 to March 26, 2014

\begin{tabular}{ll}
\hline Variable & Freq \\
\hline Main source of water & 388 \\
Pipeline water & 77 \\
Protected well or spring & 146 \\
Unprotected well or spring & \\
Time to fetch water (minutes) & \\
$\leq 30$ & 364 \\
$>30$ & 247
\end{tabular}

Amount of water collected by family (L)

$<20 \quad$ II

$20-40 \quad 239$

$40-60 \quad 161$

60-80 105

$>80 \quad 95$

Liter water/capita/head (L)

Below $4 \quad 217$

4-8 243

$>8 \quad|5|$

Latrine availability

Yes $\quad 585$

No 26

Functional latrine

Yes 582

No 3

Type of latrine

Covered traditional pit latrine $\quad 194$

Uncovered traditional pit latrine 39

Latrine to household distance $(\mathrm{m})$

$\leq 10$

$>10$

Frequency of latrine usage

Always

Sometimes or occasionally

Latrine usage

Only adult

Both adult and children

Presence of waste disposal

Yes

No

Type of waste disposal

Uncovered pit

Covered pit

Burn on pit

Distance of waste disposal ( $m$ )

$\leq 10$

$>10$

Flies observed

Yes

No

Flies breed

Yes

No

Fly breeding site

Animal dung

Open pit latrine

Decayed and rotted foods
28

requency $(n=6 I I) \quad \%$

8

7

146

364

47

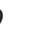

5

7

51

85

4

0.5

33.2

33.2
96.8

54.0

54.0
46.0

96.7

3.3

16.4

83.6

9.8

90.2

60.7

24.6

14.8

30.9

69.1

307

304

354

257

215

49

90
Table 2 (Continued)

\begin{tabular}{|c|c|c|}
\hline Variable & Frequency $(n=6 I I)$ & $\%$ \\
\hline \multicolumn{3}{|l|}{ Cooking place } \\
\hline In living room & 180 & 29.5 \\
\hline On the field & 69 & 11.3 \\
\hline Outside living room, its own place & 362 & 59.2 \\
\hline \multicolumn{3}{|c|}{ Availability of windows in cooking room } \\
\hline Yes & 19 & 3.1 \\
\hline No & 592 & 96.9 \\
\hline \multicolumn{3}{|l|}{ Presence of animals } \\
\hline Yes & 562 & 92.0 \\
\hline No & 49 & 8.0 \\
\hline \multicolumn{3}{|l|}{ Animals sleeping location } \\
\hline Same room where the family lives & 133 & 23.7 \\
\hline Living in house in separate room & 23 & 4.1 \\
\hline Kept in a separate house & 406 & 72.2 \\
\hline \multicolumn{3}{|l|}{ Animal dung } \\
\hline Yes & 331 & 58.9 \\
\hline No & 231 & $4 I .1$ \\
\hline \multicolumn{3}{|c|}{ Animal sleeping location distance from family $(\mathrm{m})$} \\
\hline$\leq 10$ & 476 & 84.7 \\
\hline$>10$ & 86 & 15.3 \\
\hline
\end{tabular}

inadequate knowledge were 2.8 times more likely to develop trachoma than those children from households headed by person with adequate knowledge (adjusted odds ratio $[\mathrm{AOR}]=2.8[95 \%$ confidence interval $\{\mathrm{CI}\}: 1.9,4.2])$.

The association between latrine distance to household and trachoma was maintained after adjustment of possible confounding. The odds of developing trachoma were 1.6 times more common among children of households whose latrine distance was $\leq 10 \mathrm{~m}$ compared with those located $>10 \mathrm{~m}$ away (AOR $=1.6[95 \%$ CI: 1.08, 2.4]).

The number of preschool children was associated with trachoma status. Those children from households having more than two preschool children were 2.2 times more likely to develop trachoma than those households having two or less preschool children (AOR $=2.2$ [95\% CI: 1.3, 3.7]).

Presence of flies on face of children was significantly associated with trachoma status. The odds of trachoma were 6.2 times higher among children with flies observed on the face compared with their counterparts (AOR $=6.3[95 \% \mathrm{CI}$ : $2.7,14.7])$.

Facial cleanliness of the child was significantly associated with trachoma. Those children with unclean face were 2.4 times more likely to develop trachoma than those children with clean face (AOR $=2.4$ [95\% CI: 1.5, 3.9]) (Table 4).

\subsection{Discussion}

The overall prevalence of trachoma among children aged 1-9 years in this study was $224(36.7 \%)$, which includes TF 
Table 3 Child factor of trachoma among children in Zala district from February 28 to March 26, 2014

\begin{tabular}{|c|c|c|}
\hline Variable & Frequency $(n=6 I I)$ & $\%$ \\
\hline \multicolumn{3}{|l|}{ Sex } \\
\hline Male & 286 & 46.8 \\
\hline Female & 325 & 53.2 \\
\hline \multicolumn{3}{|l|}{ Age (years) } \\
\hline $1-3$ & 296 & 48.4 \\
\hline $4-6$ & 267 & 43.7 \\
\hline $7-9$ & 48 & 7.9 \\
\hline \multicolumn{3}{|c|}{ Number of preschool children } \\
\hline$\leq 2$ & 506 & 82.8 \\
\hline$>2$ & 105 & 17.2 \\
\hline \multicolumn{3}{|l|}{ Frequency of face washing } \\
\hline More than once a day & 523 & 85.6 \\
\hline Once a day & 43 & 7.0 \\
\hline Occasionally & 45 & 7.4 \\
\hline \multicolumn{3}{|l|}{ Ocular discharge } \\
\hline Yes & 102 & 16.7 \\
\hline No & 509 & 83.3 \\
\hline \multicolumn{3}{|l|}{ Nasal discharge } \\
\hline Yes & 109 & 17.8 \\
\hline No & 502 & 82.2 \\
\hline \multicolumn{3}{|l|}{ Child education } \\
\hline Preschool child & 557 & 91.2 \\
\hline Not attending school & 27 & 4.4 \\
\hline Grade I-3 attending school & 27 & 4.4 \\
\hline \multicolumn{3}{|l|}{ Soap usage for face } \\
\hline Yes & 582 & 95.3 \\
\hline No & 29 & 4.7 \\
\hline \multicolumn{3}{|l|}{ Bathing child } \\
\hline Yes & 602 & 98.5 \\
\hline No & 9 & 1.5 \\
\hline \multicolumn{3}{|l|}{ Frequency of bathing } \\
\hline Sometimes & 374 & 61.2 \\
\hline Always & 237 & 38.8 \\
\hline \multicolumn{3}{|l|}{ Share towel } \\
\hline Yes & 172 & 28.2 \\
\hline No & 439 & 71.8 \\
\hline \multicolumn{3}{|l|}{ Flies present } \\
\hline Yes & 63 & 10.3 \\
\hline No & 548 & 89.7 \\
\hline \multicolumn{3}{|l|}{ Number of flies } \\
\hline $1-3$ & 29 & 46.0 \\
\hline $4-7$ & 23 & 36.5 \\
\hline$>7$ & 11 & 17.5 \\
\hline \multicolumn{3}{|l|}{ Child facial cleanliness } \\
\hline Clean & 460 & 75.3 \\
\hline Unclean & $|5|$ & 24.7 \\
\hline
\end{tabular}

207 (92.4\%), TI eight (3.5\%), and combination of TF/TI nine $(4 \%)$. This result was almost comparable with the prevalence of trachoma in Ethiopia, which reported $40.1 \%$ national prevalence and 33.2\% Southern regional prevalence. ${ }^{12}$ It was also consistent with studies conducted in Samburu district of Kenya, ${ }^{13}$ Hai district of Northern Tanzania, ${ }^{14}$ and in Mali, ${ }^{15}$ accounting 35\%, 34.9\%, and 34\%, respectively. However, the prevalence was lower than a report from Southern part of Sudan ${ }^{16}$ and another report from Unity state in South Sudan, ${ }^{17}$ which reported $64 \%$ and $71 \%$, respectively. The lower prevalence in our study might be because of the increment of mass antibiotic distribution coverage with better integration of health promotion on primary eye care, health information on personal and environmental hygiene of the district.

On the other hand, the prevalence of trachoma in the current study was higher than a report from Baso Liben district, ${ }^{10}$ and another report from Mojo and Lume districts ${ }^{18}$ of Ethiopia, which reported prevalence of $24.1 \%$ and $22.51 \%$ of trachoma, respectively. It was also higher than a report from Kano state of Nigeria, ${ }^{19}$ which reported $17.5 \%$ prevalence of trachoma. The higher prevalence in the current study might be due to endemicity of the disease in the district, period of study, and geographical and cultural factors. The prevalence was also beyond the WHO benchmark definition of public health importance (AT $\geq 20 \%$ ). ${ }^{20-22}$ Therefore, the finding of the current study confirmed that trachoma is still a disease of public health importance in Zala district.

In this study, it was found that children from household heads having inadequate knowledge about trachoma were 2.8 times more likely to develop trachoma compared with children from household heads who had adequate knowledge. This finding is consistent with the study conducted in Baso Liben district ${ }^{10}$ and rural zones of Ethiopia. ${ }^{23}$ It is also consistent with a similar study from Tanzania. ${ }^{24}$ It might be less access to information, education, and communication about trachoma that made the children from the household heads who had inadequate knowledge about trachoma develop trachoma.

The current study showed that the odds of developing trachoma were 1.6 times more common among children of households whose latrine distance was $\leq 10 \mathrm{~m}$ compared with those whose latrine distance was $>10 \mathrm{~m}$. This is in line with studies conducted in Gambia ${ }^{25}$ and Hawzien district, Tigray. ${ }^{26}$ On the contrary, a study from Egypt showed that the presence of a functional latrine near the house had been associated with lower trachoma prevalence. ${ }^{27}$ The decrease in latrine distance from the household possibly allowed flies to be in the house and frequent exposure of the children to the flies possibly made them develop trachoma.

Those children from households having more than two preschool children were 2.2 times more likely to develop trachoma than those households having two or less preschool children. This is consistent with a study conducted in Hai district Tanzania. ${ }^{14}$ This could be due to the fact that increases in number of preschool children decreases care 
Table 4 Multiple logistic regression predictors of trachoma among children aged I-9 years in Zala district from February 28 to 26 March 2014

\begin{tabular}{|c|c|c|c|c|}
\hline \multirow[t]{3}{*}{ Variables } & \multicolumn{2}{|c|}{ Trachoma statue } & \multirow[t]{3}{*}{ COR $(95 \% \mathrm{Cl})$} & \multirow[t]{3}{*}{ AOR $(95 \% \mathrm{Cl})$} \\
\hline & Yes & No & & \\
\hline & No (\%) & No (\%) & & \\
\hline \multicolumn{5}{|c|}{ Knowledge of trachoma } \\
\hline Inadequate knowledge & $126(56.2)$ & $119(30.7)$ & $2.9(2.06,4.07)^{*}$ & $2.8(1.9,4.2)^{*}$ \\
\hline Adequate knowledge & $98(43.8)$ & $268(69.3)$ & I & I \\
\hline \multicolumn{5}{|l|}{ Latrine distance $(\mathrm{m})$} \\
\hline$\leq 10$ & $134(59.8)$ & $196(50.6)$ & $1.5(1.04,2.02)^{*}$ & $1.6(1.09,2.4)^{*}$ \\
\hline$>10$ & $90(40.2)$ & I9I (49.4) & 1 & 1 \\
\hline \multicolumn{5}{|c|}{ Number of preschool children } \\
\hline$\leq 2$ & $166(74.1)$ & $340(87.9)$ & 1 & I \\
\hline$>2$ & $58(25.9)$ & $47(12.1)^{\prime}$ & $2.5(1.7,3.9)^{*}$ & $2.2(1.3,3.7)^{*}$ \\
\hline \multicolumn{5}{|l|}{ Flies on face } \\
\hline Yes & $53(23.7)$ & $10(2.6)$ & II.7 $(5.8,23.5)^{*}$ & $6.3(2.7,14.7)^{*}$ \\
\hline No & $17 \mid(76.3)$ & $377(97.4)$ & 1 & 1 \\
\hline \multicolumn{5}{|l|}{ Facial cleanliness } \\
\hline Clean & $130(58.0)$ & $330(85.3)$ & 1 & 1 \\
\hline Unclean & $94(42.0)$ & $57(14.7)$ & $4.2(2.8,6.2)^{*}$ & $2.4(1.5,3.9)^{*}$ \\
\hline
\end{tabular}

Note: *Significant at $P \leq 0.05$.

Abbreviations: $\mathrm{AOR}$, adjusted odds ratio; $\mathrm{Cl}$, confidence interval; $\mathrm{COR}$, Crude odds ratio.

given to the children by the household members/care givers. Moreover, depletion of family resource as a result of caring for increased number of preschool children might increase the risk of exposure to poor hygiene and consequently to Chlamydia infection.

Presence of flies on the face of children was significantly associated with trachoma status. The odds of trachoma were 6.2 times higher among children observed with flies on their face compared with their counterparts. This is in line with two studies from Mali, ${ }^{15,28}$ and a study conducted in Maksegnit town, Northwest Ethiopia ${ }^{29}$ that showed children with flies on their face were over two times more likely to have active trachoma than those children without flies on their face. Studies from Southern Sudan, ${ }^{16}$ Nigeria, ${ }^{19}$ Senegal, ${ }^{30}$ have also reported the same finding. However, it disagrees with a study conducted in Samburu district. ${ }^{13}$ The difference could be due to the endemicity of the area and low hygienic practice in which flies were attracted by unclean faces.

Facial cleanliness of the child was significantly associated with trachoma. Those children with unclean faces were two times more likely to develop trachoma than those children with clean faces. This is comparable with studies conducted in Southern Sudan, ${ }^{16}$ Kano state of Nigeria, ${ }^{19}$ Maksegnit town, Gondar, ${ }^{29}$ Kaolack district Senegal, ${ }^{30}$ Dangla, Ethiopia, ${ }^{31}$ Ankober, Ethiopia, ${ }^{32}$ and Kersa district of Southwestern Ethiopia. ${ }^{33}$ This is due to the fact that children with unclean faces could be more likely to spread ocular secretions infected with $C$. trachomatis among one another, particularly if their face is cleaned by the same cloth, unclean face produces eye discharge that attracts flies, which is the main transmission mechanism. Dacron swabs for the Chlamydia RNA polymerase chain reaction test were not done to confirm ocular chlamydia infection. This was the limitation of the study.

\section{Conclusion and recommendation}

The prevalence of trachoma among children aged 1-9 years found in Zala district was high. Among a number of risk factors, head of household having knowledge about trachoma, distance from latrine to household, number of preschool children in the household, presence of flies on the face of the child, and cleanliness of the child's face were independently associated with trachoma. Hence, it is a serious problem and requires immediate attention, such as creating an awareness program in the community, informing parents about the severity of trachoma, and encouraging children and parents to practice hand washing, proper excreta disposal, and cleanliness of surrounding areas.

\section{Acknowledgments}

The authors would like to thank Jimma University for funding the study. The authors would also like to thank Zala district principals, who gave letter of cooperation for data collection. The authors would also like to thank Orbis International Ethiopia for logistic and ophthalmic nurses support. The authors are also grateful to the participants of the study.

\section{Disclosure}

The authors report no conflicts of interest in this work. 


\section{References}

1. World Health Organization. World Health Organization Global Burden of Disease. Geneva: WHO Press; 2007.

2. Supply W, Council SC; UNICEF. Global Water Supply and Sanitation Assessment 2000 Report. New York: UNICEF; 2000.

3. Pizzarello L, Abiose A, Ffytche T, et al. VISION 2020: The Right to Sight: a global initiative to eliminate avoidable blindness. Arch Ophthalmol. 2004;122(4):615-620.

4. Melese M, Alemayehu W, Bayu S, et al. Low vision and blindness in adults in Gurage Zone, central Ethiopia. Br J Ophthalmol. 2003; 87(6):677-680.

5. Zerihun N, Mabey D. Blindness and low vision in Jimma Zone, Ethiopia: results of a population-based survey. Ophthalmic Epidemiol. 1997;4(1):19-26.

6. Berhane Y, Worku A, Bejiga A, et al. Prevalence and causes of blindness and low vision in Ethiopia. Ethiop J Heal Dev. 2007;21(3): 204-210.

7. Muñoz B, West S. Trachoma: the forgotten cause of blindness. Epidemiol Rev. 1997;19(2):205-217.

8. Thylefors B. Trachoma-new opportunities to tackle an old problem. Br J Ophthalmol. 1996;80(12):1033.

9. Negrel AD, Mariotti S. Trachoma rapid assessment: rationale and basic principles. Community Eye Health. 1999;12:51-53.

10. Ketema K, Tiruneh M, Woldeyohannes D, Muluye D. Active trachoma and associated risk factors among children in Baso Liben district of East Gojjam, Ethiopia. BMC Public Health. 2012;12(1):1.

11. World Health Organization. Primary Health Care Level Management of Trachoma. Geneva: [WHO/PBL/93.33]; 1993;4(2):461-466.

12. Berhane Y, Worku A, Bejiga A, et al. Prevalence of trachoma in Ethiopia. Ethiop J Health Dev. 2007;21(3):211.

13. Ng'ang'a ZW, Mutua DM, Mbakaya C, Muthami L. Evaluation of the risk factors associated with active trachoma among 1-9 year-old children Samburu district. Prime J Social Sci. 2015;2(11):497-501.

14. Mahande MJ, Mazigo HD, Kweka EJ. Association between water related factors and active trachoma in Hai district, Northern Tanzania. Infect Dis Poverty. 2012;1(1):1-7.

15. Hägi M, Schémann JF, Mauny F, et al. Active trachoma among children in Mali: clustering and environmental risk factors. PLoS Negl Trop Dis. 2010;4(1):e583.

16. Ngondi J, Matthews F, Reacher M, et al. Prevalence of risk factors and severity of active trachoma in southern Sudan: an ordinal analysis. Am J Trop Med Hyg. 2007;77(1):126-132.

17. Edwards T, Smith J, Sturrock HJ, et al. Prevalence of trachoma in Unity State, South Sudan: results from a large-scale population-based survey and potential implications for further surveys. PLoS Negl Trop Dis. 2012;6(4):e1585.
18. Yalew KN, Mekonnen MG, Jemaneh AA. Trachoma and its determinants in Mojo and Lume districts of Ethiopia. Pan Afr Med J. 2012; 13(Suppl 1):1-5.

19. Mpyet C, Lass BD, Yahaya HB, Solomon AW. Prevalence and risk factors for trachoma in Kano state, Nigeria. PLoS One. 2012;7(7):e40421.

20. World Health Organization. The Global Initiation for Elimination of Avoidable Blindness: WHO/Pb1/97.6/ Rev.1. Geneva: World Health Organization; 1997;8(2):1-3.

21. World Health Organization. Planning Meeting for the Global Elimination of Trachoma: Geneva. Geneva: WHO; 1996.

22. Bailey R, Lietman T. The SAFE strategy for the elimination of trachoma by 2020: will it work? Bull World Health Organ. 2001;79(3): 233-236.

23. Cumberland P, Edwards T, Hailu G, et al. The impact of community level treatment and preventative interventions on trachoma prevalence in rural Ethiopia. Int J Epidemiol. 2008;37(3):549-558.

24. West S, Muñoz B, Lynch M, et al. Impact of face-washing on trachoma in Kongwa, Tanzania. Lancet. 1995;345(8943):155-158.

25. Harding-Esch EM, Edwards T, Sillah A, et al. Risk factors for active trachoma in The Gambia. Trans R Soc Trop Med Hyg. 2008;102(12): 1255-1262.

26. Ashebir Y, Rai Sharma H, Alemu K, Kebede G. Latrine use among rural households in northern Ethiopia: a case study in Hawzien district, Tigray. Int J Environ Stud. 2013;70(4):629-636.

27. Courtright P, Sheppard J, Lane S, Sadek A, Schachter J, Dawson CR. Latrine ownership as a protective factor in inflammatory trachoma in Egypt. Br J Ophthalmol. 1991;75(6):322-325.

28. Schémann JF, Sacko D, Malvy D, et al. Risk factors for trachoma in Mali. Int J Epidemiol. 2002;31(1):194-201.

29. Shiferaw D, Moges HG. Risk factors for active trachoma among children aged 1-9 years in Maksegnit town, Gondar Zuria district, Northwest Ethiopia. Saudi Journal of Health Sciences. 2013;2(3):202-206.

30. Faye M, Kuper H, Dineen B, Bailey R. Rapid assessment for prioritisation of trachoma control at community level in one district of the Kaolack Region, Senegal. Trans R Soc Trop Med Hyg. 2006;100(2):149-157.

31. Gedefaw M, Shiferaw A, Alamrew Z, Feleke A, Fentie T, Atnafu K. Current state of active trachoma among elementary school students in the context of ambitious national growth plan: The case of Ethiopia. Health. 2013;5(11):1768-1773.

32. Golovaty I, Jones L, Gelaye B, et al. Access to water source, latrine facilities and other risk factors of active trachoma in Ankober, Ethiopia. PLoS One. 2009;4(8):e6702.

33. Ejigu M, Kariuki MM, Ilako DR, Gelaw Y. Rapid trachoma assessment in Kersa district, Southwest Ethiopia. Ethiop J Health Sci. 2013; 23(1):1-9.
Clinical Ophthalmology

\section{Publish your work in this journal}

Clinical Ophthalmology is an international, peer-reviewed journal covering all subspecialties within ophthalmology. Key topics include: Optometry; Visual science; Pharmacology and drug therapy in eye diseases; Basic Sciences; Primary and Secondary eye care; Patient Safety and Quality of Care Improvements. This journal is indexed on Submit your manuscript here: http://www.dovepress.com/clinical-ophthalmology-journal
Dovepress

PubMed Central and CAS, and is the official journal of The Society of Clinical Ophthalmology (SCO). The manuscript management system is completely online and includes a very quick and fair peer-review system, which is all easy to use. Visit http://www.dovepress.com/ testimonials.php to read real quotes from published authors. 